\title{
The Development Of Flip Book-Based E-module On The Subject Of Computer Aided Manufacturing (CAM)
}

\section{Pengembangan E-modul Berbasis Flipbook Pada Mata Kuliah Computer Aided Manufacturing (CAM)}

\author{
Muhammad Hudan Rahmat ${ }^{(1)}$ Harie Satiyadi Jaya ${ }^{(2)}$ \\ 1), 2) Pendidikan Teknik Mesin, Fakultas Keguruan dan IImu Pendidikan Universitas Palangka Raya \\ Kampus UPR Tunjung Nyaho Jl. H. Timang, 73111A \\ e-mail: hudanrahmat@fkip.upr.ac.id
}

\begin{abstract}
The research aims at developing a flipbook-based e-module on the subject of Computer Aided Manufacturing (CAM), due to the its innovative, complete, interesting, interactive, and able to hold good cognitive function of students. The e-module development stages adopt the Model of Dick \& Carey which modified into 4 stages, namely stage (1) requirement analysis, (2) product design, (3) validation and evaluation, and (4) product revision. Based on development results, data found as follows; (1) lecturer's assessment shows that the product developed come into criteria "very good" with percentage $92,05 \%$, hence e-modul can be used in learning, (2) test results on a small group shows that the product developed come into criteria "very good" with percentage $93,59 \%$, hence e-module can be used in learning, and (3) field test results shows that that the product developed come into criteria "good" with percentage $81,92 \%$, hence e-module can be used in learning with some improvement.
\end{abstract}

Key words: e-module, flipbook, CAD/CAM

\begin{abstract}
ABSTRAK
Penelitian ini bertujuan untuk mengembangkan e-modul berbasis flipbook pada mata kuliah Computer Aided Manufacturing (CAM), karena e-modul dinilai memiliki keunggulan yaitu bersifat inovatif, dapat menampilkan bahan ajar yang lengkap, menarik, interaktif, serta mampu mengemban fungsi kognitif peserta didik dengan baik. Tahap pengembangan e-modul mengadaptasi model Dick \& Carey yang dimodifikasi menjadi empat tahap, yaitu tahap (1) analisis kebutuhan, (2) desain produk, (3) validasi dan evaluasi, serta (4) revisi produk. Berdasarkan hasil pengembangan diperoleh data sebagai berikut; (1) penilaian dosen terhadap e-modul menunjukkan bahwa produk yang dikembangkan masuk dalam kriteria "sangat baik" dengan persentase 92,05\%, sehingga e-modul dapat digunakan dalam pembelajaran, (2) hasil uji coba kelompok kecil menunjukkan bahwa produk yang dikembangkan masuk dalam kriteria "sangat baik" dengan persentase 93,59\%, sehingga e-dapat digunakan dalam pembelajaran, dan (3) hasil uji coba lapangan menunjukkan bahwa produk yang dikembangkan masuk dalam kriteria "baik" dengan persentase $81,92 \%$, sehingga e-modul dapat digunakan dalam pembelajaran, namun masih perlu adanya perbaikan.
\end{abstract}

Kata kunci: e-modul, flipbook, CAD/CAM

\section{PENDAHULUAN}

Pendidikan Teknik Mesin (PTM) merupakan program studi pada Fakultas Keguruan dan IImu Pendidikan (FKIP) Universitas Palangka Raya (UPR), yang menghasilkan lulusan sebagai guru professional dan tenaga ahli di bidang teknik mesin dengan peminatan otomotif dan produksi. Program Studi PTM tergolong dalam salah satu lembaga pendidikan kejuruan karena juga bertujuan untuk membekali lulusannya dengan kompetensi tertentu agar siap pakai dalam suatu bidang pekerjaan.

Salah satu kompetensi yang harus dikuasai mahasiswa PTM konsentrasi produksi adalah membuat simulasi pemesinan dengan menggunakan komputer.
Untuk mencapai tujuan pembelajaran tersebut, maka setelah menempuh mata kuliah Computer Aided Manufacturing (CAM) mahasiswa diharapkan mampu mengaplikasikan program CAM dalam suatu proses manufaktur melalui suatu gambar kerja terkomputerisasi.

Penerapan CAM memiliki keunggulan dibandingkan dengan proses manufaktur secara manual. Banyak industri-industri manufaktur yang menggunakan mesin Computer Numerical Controlled (CNC) untuk pembuatan produk. Dengan menggunakan mesin CNC, proses pembuatan produk mulai dari pengaturan kecepatan, bentuk alat potong, pengaturan ketebalan penyayatan sampai dengan tingkat 
kehalusan dan bentuk dari produk tersebut diatur oleh komputer. Dengan adanya program bantuan, proses pemasukan data numerik tidak lagi dilakukan secara manual mengklik pada keyboard komputer mesin secara langsung dan terperinci, tetapi cukup dengan memasukan data yang telah terprogram pada disket atau media penyimpan lainnya yang telah terprogram (Yogaswara, 2008).

Hasil observasi di Program Studi PTM menunjukkan bahwa belum tersedianya modul untuk menunjang proses pembelajaran simulai pemesinan melalui software CAM. Tersedianya modul baik berupa modul elektronik maupun versi cetak dapat mempermudah mahasiswa dalam memahami materi. Permasalahan yang sering terjadi ketika mahasiswa belajar tanpa bantuan modul adalah kesulitan dalam memahami konsep dasar pada materi; (1) pembuatan desain, (2) proses simulasi, dan (3) pembuatan kode NC. Jika konsep tersebut sudah dikuasai maka mahasiswa akan lebih mudah untuk mempelajari materi selanjutnya yang lebih kompleks.

Modul adalah bahan ajar yang ditulis dengan tujuan agar peserta didik dapat belajar secara mandiri tanpa atau dengan bimbingan dosen (Lestari, 2013). Dalam mengembangkan suatu modul minimal memuat tujuan pembelajaran, materi/substansi belajar, dan evaluasi. Menurut Sudjimat (2014) untuk menghasilkan modul yang mampu meningkatkan motivasi belajar, pengembangan modul harus memperhatikan karakteristik yang diperlukan sebagai modul, yaitu: (1) self instructional, (2) self contained, (3) stand alone (berdiri sendiri), (4) adaptif, dan (5) user friendly.

E-modul adalah modul versi elektronik dimana akses dan penggunaannya dilakukan melalui alat elektronik seperti komputer, laptop, tablet atau bahkan smartphone. E-modul dinilai bersifat inovatif karena dapat menampilkan bahan ajar yang lengkap, menarik, interaktif, dan mengemban fungsi kognitif yang bagus. Kelebihan e-modul yaitu dapat meningkatkan keterampilan berpikir kritis peserta didik (Eldarni, 2019).

Beberapa penelitian menunjukkan e-modul efektif digunakan dalam pembelajaran yang berkaitan dengan penggunaan software. Penelitian Lumbantobing (2017) menunjukkan respon pengguna terhadap e-modul dalam hal ini guru dan siswa diperoleh kategori "sangat baik" dengan persentase kelayakan masingmasing adalah $84,38 \%$ dan $81,67 \%$. Kemudian hasil penelitian Purwoko dkk. (2012); Sanjaya (2012); Wijanarka (2013) menunjukkan penggunaan modul dan perangkat lunak $C A D / C A M$ dapat meningkatkan kompetensi dan keaktifan peserta didik.

Bentuk e-modul bervariasi dan dapat dibuat dengan menggunakan software. Flipbook makers adalah salah satu software yang berguna untuk membuat aplikasi buku elektronik, sedangkan buku elektronik adalah buku yang dapat dibaca melalui komputer (Dahar, 2011). Salah satu keunggulan dari aplikasi ini adalah mampu memberi efek flip, yaitu membuka atau membalik lembar demi lembar halaman buku sehingga seperti membaca buku sungguhan (Asmi dkk., 2018).

Peran e-modul dalam konteks mata kuliah CAM adalah sebagai panduan untuk melakukan proses simulasi pemesinan melalui software. Terdapat dua software yang digunakan pada mata kuliah CAM, yakni Solidwork, dan Mastercam. Solidwork adalah program untuk membuat desain sistem mekanis yang memungkinkan desainer dengan cepat membuat sketsa rancangan, bereksperimen dengan fitur dan dimensi, serta menghasilkan model 3D dan gambar yang mendetail. Sedangkan Mastercam adalah program untuk membuat maket produk mesin dengan komputer dalam bentuk program atau gambar terprogram yang dapat diakses pada mesin CNC (Yogaswara, 2008). Kombinasi penggunaan kedua software ini bertujuan agar mahasiswa dapat menguasai materi CAM secara komprehensif.

Sebagai solusi dari permasalahan yang ada, maka penelitian ini bertujuan untuk mengembangkan Emodul berbasis flipbook pada mata kuliah CAM. Adanya e-modul pada mata kuliah ini diharapkan dapat digunakan oleh mahasiswa sebagai panduan yang dapat mempermudah memahami materi CAM dan mampu belajar secara mandiri maupun terbimbing.

\section{METODE}

Jenis penelitian ini adalah penelitian pengembangan atau Research and Development (R\&D). Model pengembangan Dick \& Carey yang digunakan pada penelitian ini diadaptasi menjadi empat tahap, yaitu; (1) tahap analisis kebutuhan modul, (2) tahap desain produk, (3) tahap validasi dan evaluasi, serta (4) tahap revisi.

Instrumen yang digunakan pada penelitian ini berupa angket atau kuesioner. Instrumen penelitian ini mengadaptasi instrumen Lumbantobing (2017) tentang pengembangan e-modul. Terdapat dua jenis angket yang digunakan yaitu angket untuk dosen pengampu mata kuliah dan angket untuk mahasiswa. Angket untuk dosen pengampu mata kuliah berisi tinjauan tentang penggunaan e-modul dilihat dari aspek materi pembelajaran dan media pembelajaran. Angket diberikan pada dosen yang terdiri dari 22 butir pernyataan dengan sistem penilaian skala likert dengan interval $1 \mathrm{~s} / \mathrm{d}$. 4. Angket untuk mahasiswa menggunakan angket yang berisi tinjauan tentang penggunaan e-modul dilihat dari aspek materi, media, fungsi, dan efektivitas dalam pembelajaran. Angket diberikan pada mahasiswa yang terdiri dari 26 butir pernyataan dengan sistem penilaian skala likert dengan interval $1 \mathrm{~s} / \mathrm{d} 4$.

Sebelum diujicobakan ke pengguna, dilakukan valiadasi ahli materi dan ahli media guna memperolah kritik dan saran untuk perbaikan dan peningkatan 
kualitas e-modul. Ahli materi menilai e-modul pada aspek self instructional, self contained, stand alone, adaptive dan user friendly, sedangkan ahli media menilai e-modul pada aspek verbal, visual, pemrograman dan penyusun modul.

Penelitian ini menggunakan teknik analisis deskriptif untuk mendeskripsikan data hasil pengisian angket dari responden. Untuk keperluan analisis kuantitatif, data yang telah dikumpulkan dari angket diberi kategori berbobot skor $1 \mathrm{~s} / \mathrm{d} 4$. Analisis data angket diolah dengan menjumlahkan bobot skor alternatif jawaban yang telah dipilih pada masingmasing pertanyaan yang diberikan (n). Jumlah itu kemudian dibagi dengan skor ideal yang dapat diperoleh (N). Hasil itu kemudian dikalikan 100\% untuk mendapatkan persentasenya. Berikut panduan kriteria untuk mendeskripsikan data kuesioner.

$$
\text { Persentase }=\frac{\Sigma}{N} x 100 \%
$$

Gambar 1. Rumus Persentase

Tabel 1. Kriteria Deskripsi Data

\begin{tabular}{|c|c|c|}
\hline Persentase & Keterangan & Tindak lanjut \\
\hline $90-100$ & Sangat Baik & Produk baru siap dimanfaatkan untuk kegiatan pembelajaran \\
\hline $75-90$ & Baik & $\begin{array}{l}\text { Produk dapat dilanjutkan dengan menambahkan sesuatu yang kurang, dan } \\
\text { melakukan pertimbangan-pertimbangan tertentu }\end{array}$ \\
\hline $60-80$ & Cukup & $\begin{array}{l}\text { Merevisi dengan meneliti kembali secara seksama dan mencari kelemahan- } \\
\text { kelemahan produk untuk disempurnakan }\end{array}$ \\
\hline$<60$ & Kurang & Merevisi produk secara besar-besaran dan mendasar \\
\hline
\end{tabular}

\section{HASIL DAN PEMBAHASAN}

\section{Hasil Analisis Kebutuhan}

Anailsis kebutuhan modul merupakan kegiatan menganalisis kompetensi yang akan dicapai sebagai dasar menentukan jumlah dan cakupan materi yang dibutuhkan untuk mencapai kompetensi tersebut. Analisis kompetensi didasarkan pada Rencana Pembelajaran Semester (RPS) yang digunakan pada mata kuliah CAM. Hasil studi pendahuluan terhadap kebutuhan modul CAM ditunjukkan pada Tabel 2.

Tabel 2. Hasil Analisis Kebutuhan Modul

\begin{tabular}{|c|c|c|c|}
\hline No. & Standar Kompetensi & Materi & Software \\
\hline 1. & $\begin{array}{l}\text { Menjelaskan aplikasi CAD/CAM dalam suatu } \\
\text { proses manufaktur }\end{array}$ & $\begin{array}{l}\text { Pembuatan sketch. } \\
\text { 1. Memahami penggunaan software } \\
\text { 2. Menggunakan tool sketch } 2 \mathrm{~d} \text { (line, } \\
\text { cirle, reactangle) } \\
\text { 3. Menggunakan tool edit (trim, extend, } \\
\text { mirror) }\end{array}$ & Solidwork \\
\hline 2. & $\begin{array}{l}\text { Menggambar/melakukan pemodelan } \\
\text { komponen produk (desain manufaktur) 2D dan } \\
\text { 3D dengan menggunakan aplikasi CAD/CAM }\end{array}$ & $\begin{array}{l}\text { Pembuatan desain komponen. } \\
\text { 1. Menggunakan tool extrude } \\
\text { 2. Menggunakan tool revolve } \\
\text { 3. Melakukan editing feature }\end{array}$ & Solidwork \\
\hline 3. & $\begin{array}{l}\text { Menggambar/melakukan pemodelan rakitan } \\
\text { (assembly), serta melakukan pelepasan } \\
\text { komponen (diss-assembly) dan animasinya } \\
\text { dengan aplikasi CAD/CAM }\end{array}$ & $\begin{array}{l}\text { Proses perakitan komponen. } \\
\text { 1. Melakukan assembly komponen } \\
\text { (constraint, coincident, paralel, } \\
\text { tangent) } \\
\text { 2. Melakukan diss-assembly komponen }\end{array}$ & Solidwork \\
\hline 4. & $\begin{array}{l}\text { Menyiapkan dokumen gambar untuk } \\
\text { menunjang proses manufaktur }\end{array}$ & $\begin{array}{l}\text { Pembuatan gambar kerja. } \\
\text { 1. Membuat gambar kerja sederhana } \\
\text { (single part drawing) } \\
\text { 2. Membuat gambar kerja kompleks } \\
\text { (assembly drawing) }\end{array}$ & Solidwork \\
\hline 5. & $\begin{array}{l}\text { Melakukan simulasi pemesinan menggunakan } \\
\text { aplikasi CAM dan ekspor kode NC }\end{array}$ & $\begin{array}{l}\text { Pembuatan simulasi pemesinan dan } \\
\text { ekspor kode NC. } \\
\text { 1. Memahami penggunaan software }\end{array}$ & Mastercam \\
\hline
\end{tabular}




\section{mastercam}

2. Membuat simulasi pemesinan bubut (facing, champer, contour)

3. membuat simulasi pemesinan frais

(facing, contour, pocket)

4. Membuat kode NC dari hasil simulasi

\section{Hasil Desain Produk}

Hasil akhir e-modul disimpan dalam bentuk file .exe dengan ukuran 15,93 megabyte $(\mathrm{mb})$ yang dapat dibuka secara offline. Berikut disajikan beberapa capture dari desain produk yang dihasilkan.

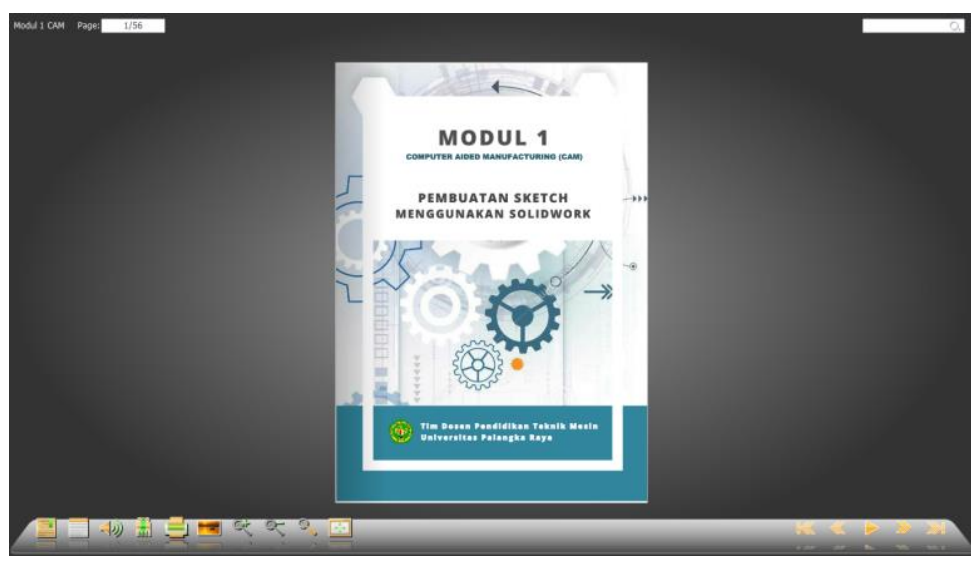

Gambar 2. Tampilan Beranda E-modul

Pada gambar beranda ditampilkan cover e-modul CAM. Secara default pengguna diarahkan ke halaman ini ketika aplikasi pertama kali dibuka.

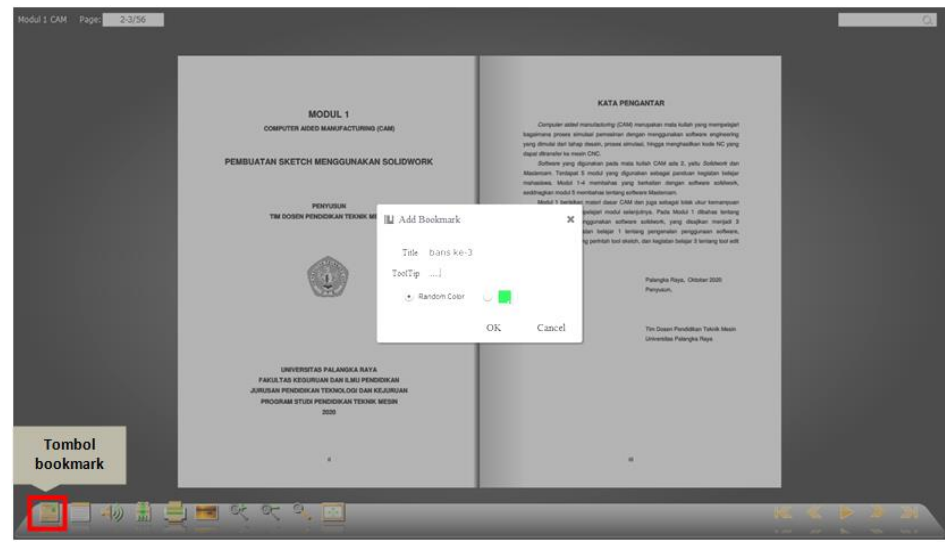

Gambar 2. Tampilan Menu Bookmark

Tombol bookmark berfungsi untuk menandai halaman. Hal ini berguna untuk membantu mahasiswa menandai halaman mana yang sudah dan yang belum dipelajari, atau menambahkan catatan dalam e-modul. 


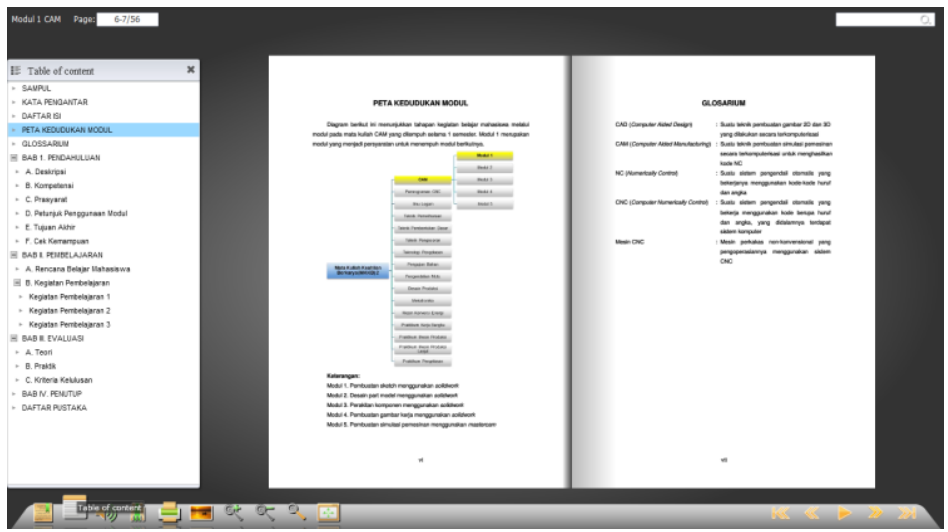

Gambar 3. Tampilan Menu Table of Content

Tombol table of content berfungsi untuk menampilkan daftar isi, sehingga memudahkan untuk pencarian bab atau sub bab pada e-modul. Dengan meng-klik salah satu menu pada daftar isi maka pengguna diarahkan langsung ke halaman yang diinginkan.

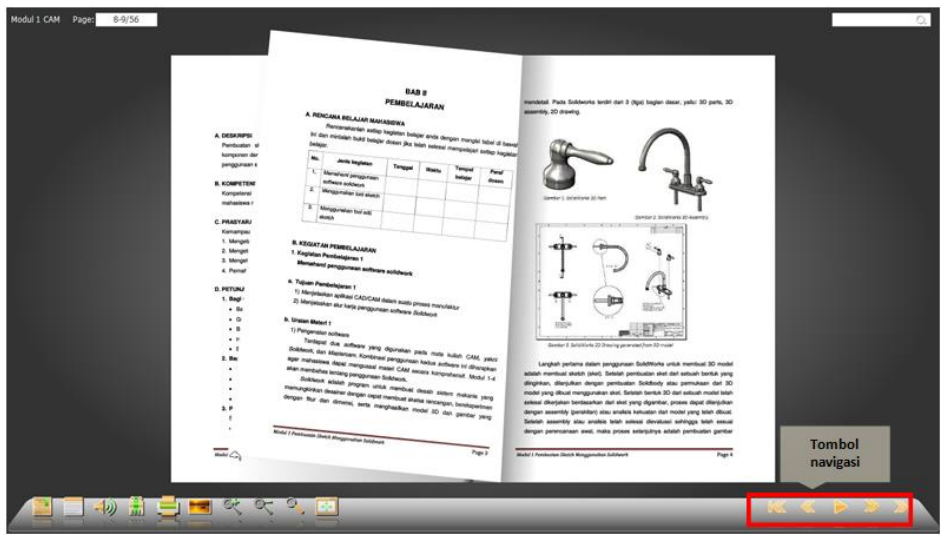

Gambar 4. Tampilan Tombol Navigasi

Tombol navigasi berfungsi untuk mengoperasikan e-modul secara otomatis maupun secara manual. Terdapat 5 tombol yang berfungsi untuk pengoperasian ini, antara lain: tombol play untuk memutar e-modul secara otomatis dari halaman awal sampai akhir, first page untuk menuju ke halaman paling awal, last page untuk menuju halaman terakhir, next page untuk menuju ke halaman selanjutnya, dan previous page untuk menuju ke halaman sebelumnya.

\section{Hasil Analisis Data}

Validasi Ahli Materi

Tabel 2. Data Validasi Ahli Materi

\begin{tabular}{ccc}
\hline Validator ( $\mathbf{n}$ ) & Skor total $(\Sigma)$ & Skor Maksimal ( N ) \\
\hline $\mathrm{A}$ & 86 & 92 \\
\hline Persentase & $=\frac{\Sigma}{N} \times 100 \%$ \\
Persentase & $=\frac{86}{92} \times 100 \%$ \\
Persentase & $=93,48 \%$
\end{tabular}

Diperoleh nilai akhir kevalidan e-modul adalah 93,48\% dengan 23 kriteria penilaian, dimana skor tertinggi adalah 4. Dilihat dari sisi materi dapat dikatakan bahwa E-modul berbasis flipbook pada matakuliah CAM yang dikembangkan tergolong dalam kriteria sangat valid/sangat baik dan dapat digunakan dalam proses pembelajaran. 


\section{Validasi Ahli Media}

Tabel 3. Data Validasi Ahli Media

\begin{tabular}{ccc}
\hline Validator ( $\mathbf{n})$ & Skor total $(\Sigma)$ & Skor Maksimal ( N ) \\
\hline $\mathrm{A}$ & 93 & 100 \\
\hline & Persentase $=\frac{\sum}{N} \times 100 \%$ \\
& Persentase $=\frac{93}{100} \times 100 \%$ \\
Persentase & $=93 \%$
\end{tabular}

Diperoleh nilai akhir kevalidan e-modul adalah 93\% dengan 25 kriteria penilaian, dimana skor tertinggi adalah 4. Dilihat dari sisi media dapat dikatakan bahwa E-modul berbasis flipbook pada matakuliah CAM yang dikembangkan tergolong dalam kriteria sangat valid/sangat baik dan dapat digunakan dalam proses pembelajaran.

\section{Respon Dosen}

Tabel 4. Data Respon Dosen

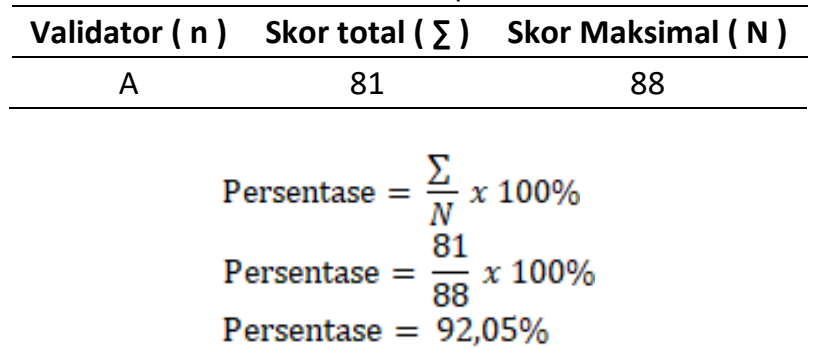

Diperoleh nilai akhir kevalidan e-modul adalah 92,05\% dengan 22 kriteria penilaian, dimana skor tertinggi adalah 4. Dilihat dari sisi materi dapat dikatakan bahwa E-modul berbasis flipbook pada matakuliah CAM yang dikembangkan tergolong dalam kriteria sangat valid/sangat baik dan dapat digunakan dalam proses pembelajaran.

\section{Uji Coba Kelompok Kecil}

Berikut adalah hasil analisis data uji coba kelompok kecil yang diperoleh dari 3 responden yaitu mahasiswa Program Studi Pendidikan Teknik Mesin FKIP UPR angkatan 2017.

Tabel 5. Data Uji Coba Kelompok Kecil

\begin{tabular}{ccc}
\hline Mahasiswa ( $\mathbf{n})$ & Skor total ( $\Sigma$ ) & Skor Maksimal (N) \\
\hline A & 102 & 104 \\
B & 104 & 104 \\
C & 86 & 104 \\
\hline
\end{tabular}

$$
\begin{aligned}
& \text { Persentase }=\frac{\sum n}{3 \times N} \times 100 \% \\
& \text { Persentase }=\frac{292}{3 \times 104} \times 100 \% \\
& \text { Persentase }=93,59 \%
\end{aligned}
$$

Diperoleh nilai akhir kevalidan e-modul adalah 93,59\% dengan 26 kriteria penilaian, dimana skor tertinggi adalah 4. Dilihat dari sisi media dapat dikatakan bahwa E-modul berbasis flipbook pada matakuliah CAM yang dikembangkan tergolong dalam kriteria sangat valid/sangat baik dan dapat digunakan dalam proses pembelajaran.

\section{Uji Coba Lapangan}

Berikut adalah hasil analisis data uji coba lapangan yang diperoleh dari 5 responden yaitu mahasiswa Program Studi Pendidikan Teknik Mesin FKIP UPR angkatan 2018. 
Tabel 6. Data Uji Coba Lapangan

\begin{tabular}{ccc}
\hline Mahasiswa ( n ) & Skor total ( $\Sigma$ ) & Skor Maksimal (N) \\
\hline A & 79 & 104 \\
B & 90 & 104 \\
C & 75 & 104 \\
D & 78 & 104 \\
E & 104 & 104 \\
\hline
\end{tabular}

$$
\begin{aligned}
& \text { Persentase }=\frac{\sum n}{3 x N} \times 100 \% \\
& \text { Persentase }=\frac{292}{5 \times 104} \times 100 \% \\
& \text { Persentase }=81,92 \%
\end{aligned}
$$

Diperoleh nilai akhir kevalidan e-modul adalah 81,92\% dengan 26 kriteria penilaian, dimana skor tertinggi adalah 4. Dilihat dari sisi media dapat dikatakan bahwa E-modul berbasis flipbook pada matakuliah CAM yang dikembangkan tergolong dalam kriteria valid/baik, sehingga dapat digunakan dalam proses pembelajaran dengan menambahkan sesuatu yang kurang, melakukan pertimbangan-pertimbangan tertentu.

Berdasarkan data yang telah dipaparkan maka sajian data penelitian ini dapat diringkas seperti pada Tabel 7

\begin{tabular}{|c|c|c|c|}
\hline No. & Data & Persentase & Kriteria \\
\hline 1. & Ahli Materi & $93,48 \%$ & $\begin{array}{l}\text { Sangat Baik/Sangat Valid dan dapat digunakan dalam } \\
\text { pembelajaran }\end{array}$ \\
\hline 2. & Ahli Media & $93,00 \%$ & $\begin{array}{l}\text { Sangat Baik/Sangat Valid dan dapat digunakan dalam } \\
\text { pembelajaran }\end{array}$ \\
\hline 3. & Respon Dosen & $92,05 \%$ & $\begin{array}{l}\text { Sangat Baik/Sangat Valid dan dapat digunakan dalam } \\
\text { pembelajaran }\end{array}$ \\
\hline 4. & Uji Coba Kelompok Kecil & $93,59 \%$ & $\begin{array}{l}\text { Sangat Baik/Sangat Valid dan dapat digunakan dalam } \\
\text { pembelajaran }\end{array}$ \\
\hline 5. & Uji Coba Lapangan & $81,92 \%$ & $\begin{array}{l}\text { Baik/Valid dan dapat digunakan dalam pembelajaran, } \\
\text { namun masih perlu adanya perbaikan }\end{array}$ \\
\hline
\end{tabular}
berikut.

Tabel 7. Rekapitulasi Data Hasil Pengembangan

\section{KESIMPULAN DAN SARAN}

Beberapa poin yang menjadi kesimpulan pada penelitian ini adalah; (1) penilaian dosen terhadap emodul menunjukkan bahwa produk yang dikembangkan masuk dalam kriteria "sangat baik" dengan persentase $92,05 \%$, sehingga e-modul dapat digunakan dalam pembelajaran, (2) hasil uji coba kelompok kecil menunjukkan bahwa produk yang dikembangkan masuk dalam kriteria "sangat baik" dengan persentase 93,59\%, sehingga e-modul dapat digunakan dalam pembelajaran, (3) kemudian hasil uji coba lapangan menunjukkan bahwa produk yang dikembangkan masuk dalam kriteria "baik" dengan persentase $81,92 \%$, sehingga e-modul dapat digunakan dalam pembelajaran, namun masih perlu adanya perbaikan.

Bagi penelitian selanjutnya dalam rangka penyempurnaan e-modul, disarankan; (1) agar lebih memperhatikan penggunaan bahasa dan istilah, sehingga peserta didik lebih mudah mengerti dan tidak bosan, dan (2) e-modul yang dihasilkan diharapkan dapat diakses menggunakan laptop maupun smartphone, karena keterbatasan pada penelitian ini emodul hanya dapat diakses melalui laptop.

\section{UCAPAN TERIMA KASIH}

Ucapan terima kasih ditujukan kepada pihak yang telah mendanai penelitian ini. Melalui pendanaan DIPA PNBP Universitas Palangka Raya Tahun 2020, maka penelitian ini dapat terselesaikan dengan baik. Selain itu, ucapan terima kasih ditujukan kepada pihak FKIP UPR yang telah mengkoordinir hibah penelitian dari tahap awal sampai tahap pelaporan.

\section{DAFTAR PUSTAKA}

Asmi, Adhitya Rol., Surbakti, Aulia Novemy Dhita B. \& Hudaidah C. (2018). Pengembangan E-Modul Berbasis Flip Book Maker Materi Pendidikan Karakter untuk Pembelajaran Mata Kuliah Pancasila MPK Universitas Sriwijaya. JPIS Jurnal Pendidikan IImu Sosial, 27(1): 1-10. 
Dahar, R.W. (2011). Teori-teori Belajar dan Pembelajaran. Jakarta: Penerbit Airlangga.

Eldarni, Eza Yayang. (2019). Pengembangan E-Modul Berbasis Web dengan Menggunakan Aplikasi Moodle pada Mata Kuliah Pengelolaan Perpustakaan. Edutech, 18(1): 25-36.

Lestari, Ika. (2013). Pengembangan Bahan Ajar Berbasis Kompetensi. Padang: Akademia Permata.

Lumbantobing, Marko Ayaki. (2017). Pengembangan EModul Interaktif untuk Discovery Learning pada Pembelajaran Mekanika Teknik dan Elemen Mesin di SMK Negeri 1 Sedayu. Universitas Negeri Yogyakarta: Tesis Tidak Diterbitkan.

Purwoko, Bambang Setyo Hari., Wijanarka, Bernardus Sentot \& Rahdiyanta, Dwi. (2012). Pengembangan Materi dan Media Pembelajaran Teknik Pemesinan
CNC Untuk SMK. Ringkasan Laporan Penelitian FT UNY.

Sanjaya, Dangu Bagus. (2012). Pengembangan Modul Penggunaan Mastercam Sebagai Media Simulator Pada Mata Pelajaran Memprogram Mesin NC/CNC Di SMK Negeri 2 Klaten. Skripsi FT UNY.

Sudjimat, Dwi Agus. (2014). Perencanaan Pembelajaran Kejuruan. Malang: Universitas Negeri Malang.

Wijanarka, Bernardus Sentot., Rahdiyanta, Dwi. \& Purnomo, Edi. (2013). Penerapan Modul Pembelajaran Untuk Meningkatkan Kompetensi Siswa Pada Pembelajaran CAD dan Pemesinan CNC di SMK. Ringkasan Laporan Penelitian FT UNY.

Yogaswara, Eka. (2008). Menggunakan CAD/CAM dengan Mastercam. Bandung: CV. Armico. 